\title{
Electron Backscatter Diffraction: An Important Tool for Analyses of Structure-Property Relationships in Thin-Film Solar Cells
}

\author{
D. ABOU-RAS,${ }^{1,5}$ J. KAVALAKKATT, ${ }^{1}$ M. NICHTERWITZ, ${ }^{1}$ N. SCHÄFER, ${ }^{1}$ \\ S. HARNDT, ${ }^{1}$ A.J. WILKINSON,${ }^{2}$ K. TSYRULIN, ${ }^{3}$ H. SCHULZ, ${ }^{3}$ \\ and F. BAUER ${ }^{4}$ \\ 1.-Helmholtz-Zentrum Berlin für Materialien und Energie GmbH, Hahn-Meitner-Platz 1, 14109 \\ Berlin, Germany. 2.-Department of Materials, University of Oxford, Parks Road, Oxford OX1 \\ 3PH, UK. 3.-Carl Zeiss Microscopy GmbH, Carl-Zeiss-Strasse 56, 73447 Oberkochen, Germany. \\ 4.-Oxford Instruments $\mathrm{GmbH}$, NanoAnalysis, Otto-von-Guericke-Ring 10, 65205 Wiesbaden, \\ Germany. 5.—e-mail: daniel.abou-ras@helmholtz-berlin.de
}

\begin{abstract}
The present work gives an overview of the application of electron backscatter diffraction (EBSD) in the field of thin-film solar cells, which consist of stacks of polycrystalline layers on various rigid or flexible substrates. EBSD provides access to grain-size and local-orientation distributions, film textures, and grain-boundary types. By evaluation of the EBSD patterns within individual grains of the polycrystalline solar cell layers, microstrain distributions also can be obtained. These microstructural properties are of considerable interest for research and development of thin-film solar cells. Moreover, EBSD may be performed three-dimensionally, by alternating slicing of cross sections in a focused ion-beam machine and EBSD acquisition. To relate the microstructural properties to the electrical properties of individual layers as well as to the device performances of corresponding solar cells, EBSD can be combined with electron-beam-induced current and cathodoluminescence measurements and with various scanning-probe microscopy methods such as Kelvin-probe force, scanning spreading resistance, or scanning capacitance microscopy on identical specimen positions. Together with standard device characterization of thin-film solar cells, these scanning microscopy measurements provide the means for extensive analysis of structure-property relationships in solar-cell stacks with polycrystalline layers.
\end{abstract}

\section{INTRODUCTION}

Thin-film solar cells are considered inorganic, polycrystalline layer stacks. Thus, they do not require any single-crystal substrates for epitaxial growth. To date, thin-film solar cells have already entered the state of mass production with record power-conversion efficiencies of up to more than $20 \%$ on the lab scale. ${ }^{1}$ This efficiency level has been obtained by using $n^{+}-\mathrm{ZnO} / n-\mathrm{CdS} / p-\mathrm{Cu}(\mathrm{In}, \mathrm{Ga}) \mathrm{Se}_{2} /$ Mo layer stacks on rigid glass or on flexible polyimide substrates. Note that in general, the pentary $\mathrm{Cu}(\mathrm{In}, \mathrm{Ga})(\mathrm{Se}, \mathrm{S})_{2}$ alloy system has been investigated and developed over the years, where variation in the $\mathrm{In}, \mathrm{Ga}, \mathrm{S}$, and Se concentrations allows for tuning the effective band-gap energy between about $1.0 \mathrm{eV}$ for $\mathrm{CuInSe}_{2}$ and about $2.4 \mathrm{eV}$ for $\mathrm{CuGaS}_{2}$. The reader is referred to Fig. 1 for a corresponding scanning electron microscopy (SEM) image and schematics of operation of a $\mathrm{Cu}(\mathrm{In}, \mathrm{Ga}) \mathrm{Se}_{2}$ thin-film solar cell.

Furthermore, solar cells based on CdTe/CdS $p$ - $n$ heterojunctions exhibit power-conversion efficiencies of up to almost $19 \% .^{2}$ With the aim of reducing material costs substantially at still competitive device performances, In and $\mathrm{Ga}$ in $\mathrm{Cu}(\mathrm{In}, \mathrm{Ga})(\mathrm{S}, \mathrm{Se})_{2}$ layers have been replaced by $\mathrm{Zn}$ and $\mathrm{Sn}$, resulting in efficiency levels of currently up to about $11 \%{ }^{3}$ Despite extensive research efforts on Si-based, thinfilm solar cells over several decades, corresponding power-conversion efficiencies for single-junction devices have not exceeded the $11 \%$ level. ${ }^{4}$

The analysis of the microstructure, i.e., of extended structural defects in individual layers, but 
also of grain-size, strain, and local-orientation distributions, as well as of integral thin-film textures, is an important part of the research and development of thin-film solar cells. Ultimately, it is essential to relate the microstructural (and also compositional) properties to the device performance of a solar cell, in order to reveal how the microstructure affects the power-conversion efficiency-usually referred to as a structure-property relationship. Electron backscatter diffraction (EBSD) in a scanning electron microscope provides access to various microstructural properties. Moreover, when combined with other SEM techniques such as electron-beam-induced current (EBIC) or cathodoluminescence (CL) and various scanningprobe microscopy (SPM) methods such as Kelvinprobe force (KPFM), scanning spreading resistance (SSRM), or scanning capacitance microscopy (SCM) on identical specimen positions, detailed insight on structure-property relationships can be obtained.

The present work gives an overview of the current status of EBSD applied on thin-film solar cells, particularly when combining this technique with various other SEM and SPM methods on identical specimen positions.

\section{EXPERIMENTAL DETAILS}

Details on production of thin-film solar cells can be found in various publications on this topic (e.g., Refs. 5 and 6). Plan-view or cross-section specimens for EBSD were prepared either by mechanical and Ar-ion polishing or by use of a focused-ion beam (FIB) machine. Especially for $\mathrm{Cu}(\mathrm{In}, \mathrm{Ga})(\mathrm{S}, \mathrm{Se})_{2}$ and $\mathrm{Cu}_{2} \mathrm{ZnSn}(\mathrm{S}, \mathrm{Se})_{4}$ thin films, the sputtering of these materials by a Ga-ion beam in a FIB machine is incongruent, resulting in the formation of $\mathrm{Cu}$-agglomerates at the surface, ${ }^{7}$ which may be

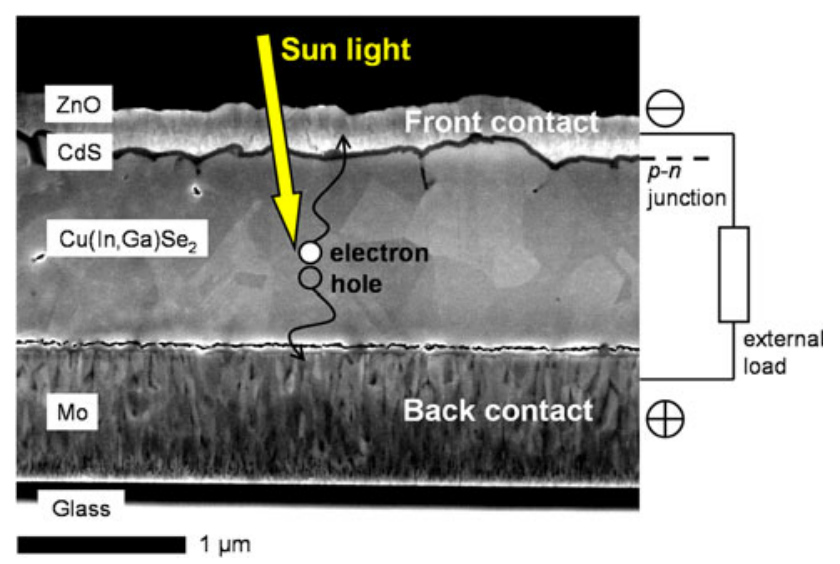

Fig. 1. SEM image of a thin-film solar cell consisting of a $n^{+}-\mathrm{ZnO} /$ $n$-CdS/p-Cu(In,Ga)Se $/$ Mo/glass stack, as well as its mode of operation. Upon illumination by sunlight, electron-hole pairs are generated, mainly in the $\mathrm{Cu}(\mathrm{In}, \mathrm{Ga}) \mathrm{Se}_{2}$ absorber layer, and separated when reaching the space-charge region of the diode (not shown here). The resulting charge densities at the $\mathrm{ZnO}$ and Mo contacts can be used to operate an external load. removed by either introducing $\mathrm{XeF}_{2}$ gas or cooling the specimen during slicing.

EBSD maps given in the present work were obtained using either an Oxford Instruments NordlysII or NordlysNano cameras on various scanning electron microscopes and FIB machines (LEO GEMINI 1530, Zeiss UltraPlus, Zeiss NVision). EBSD acquisition and evaluation have been performed using the HKL Channel5, FastAcquisition or the AZtec software packages. Evaluation of stored EBSD patterns for strain/stress analysis within individual grains were conducted by use of the CrossCourt 3 software (BLG Productions).

\section{EBSD DATA FROM THIN-FILM SOLAR CELLS}

EBSD maps contain various types of information on microstructural properties of a polycrystalline thin film, as it is shown in Fig. 2 for a $\mathrm{ZnO} / \mathrm{CdS} /$ $\mathrm{CuInS}_{2} / \mathrm{Mo}$ /glass stack prepared in cross section. Pattern-quality maps (Fig. 2a) give direct account on the quality of the specimen preparation as well as on positions of grain boundaries, while orientation-distribution maps (Fig. 2c) represent the local orientation of each grain (with respect to a reference coordinate system). From the orientations of two neighboring grains (i.e., the corresponding point lattices), their misorientation can be calculated. The related symmetry of a grain boundary may be expressed by the $\Sigma$ value, ${ }^{8}$ where grain boundaries with $\Sigma=3$ are considered those with particularly high symmetry (highlighted by red lines in Fig. 2b).

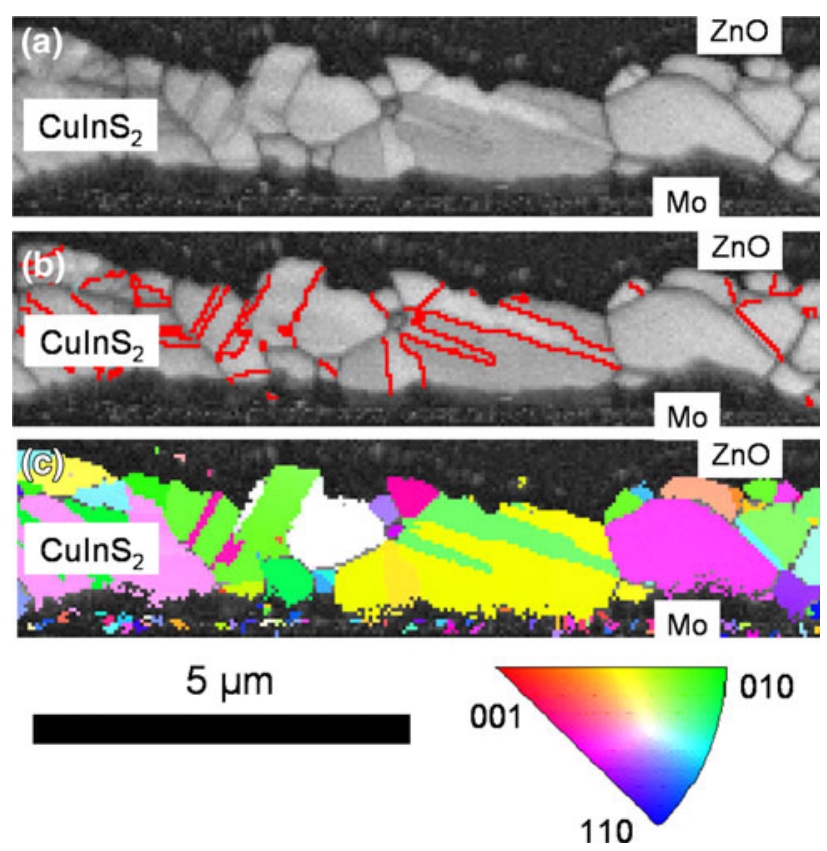

Fig. 2. EBSD pattern-quality map (a), with $\Sigma 3$ grain boundaries highlighted by red lines (b), and orientation-distribution map (c) acquired in cross section on a $\mathrm{ZnO} / \mathrm{CdS} / \mathrm{CulnS}_{2} / \mathrm{Mo} /$ glass solar-cell stack (Color figure online). 
Electron Backscatter Diffraction: An Important Tool for Analyses of Structure-Property Relationships in Thin-Film Solar Cells

In all relevant materials used as absorber layers in thin-film solar cells $\left(\mathrm{Si}, \mathrm{CdTe}, \mathrm{Cu}(\mathrm{In}, \mathrm{Ga})(\mathrm{S}, \mathrm{Se})_{2}\right.$, and $\left.\mathrm{Cu}_{2} \mathrm{ZnSn}(\mathrm{S}, \mathrm{Se})_{4}\right)$, the relative frequency of $\Sigma 3$ grain boundaries, of which most may be considered twin boundaries, is rather high, i.e., typically $50 \%$ and more (see Fig. 3). As a matter of fact, all these elemental and compound semiconductors exhibit adamantine crystal structures; i.e., they are related to the diamond lattice. During growth and cooling down, the layers are stressed considerably, and for at least partial reduction of stress/strain, the formation of twin boundaries represents an appropriate mechanism.

We found that the $\Sigma$ values of grain boundaries other than $\Sigma=3$ (twins) cannot be identified unambiguously in the absorber layers of thin-film solar cells. Thus, we divide grain boundaries into $\Sigma 3$ (twin) boundaries and non- $\Sigma 3$ (random) grain boundaries.

From EBSD data containing a large number of grains (at least several hundreds), decent grain-size distributions can be extracted. ${ }^{9}$ Datasets from such EBSD measurements provide also information on integral film textures,${ }^{10}$ which agree well with corresponding measurements by means of x-ray diffraction. ${ }^{11}$ It is possible to trace back from EBSD data obtained on $\mathrm{Cu}(\mathrm{In}, \mathrm{Ga})(\mathrm{S}, \mathrm{Se})_{2}$ layers how twinning occurred comparing the local orientations with the theoretically possible changes in orientation by twinning. ${ }^{12,13}$ The technique has been shown to be an important tool for site-specific specimen preparation of needle-type samples fabricated for the analysis of extended structural defects in thinfilm solar cells by means of atom-probe tomography. ${ }^{14}$

EBSD is a useful technique for studying the growth behavior of chemical-bath-deposited CdS and $\mathrm{Zn}(\mathrm{O}, \mathrm{S})$ buffer layers on $\mathrm{Cu}(\mathrm{In}, \mathrm{Ga}) \mathrm{Se}_{2} \cdot{ }^{15}$ Moreover, it has been applied on $\mathrm{Cu}(\mathrm{In}, \mathrm{Ga})(\mathrm{S}, \mathrm{Se})_{2}$

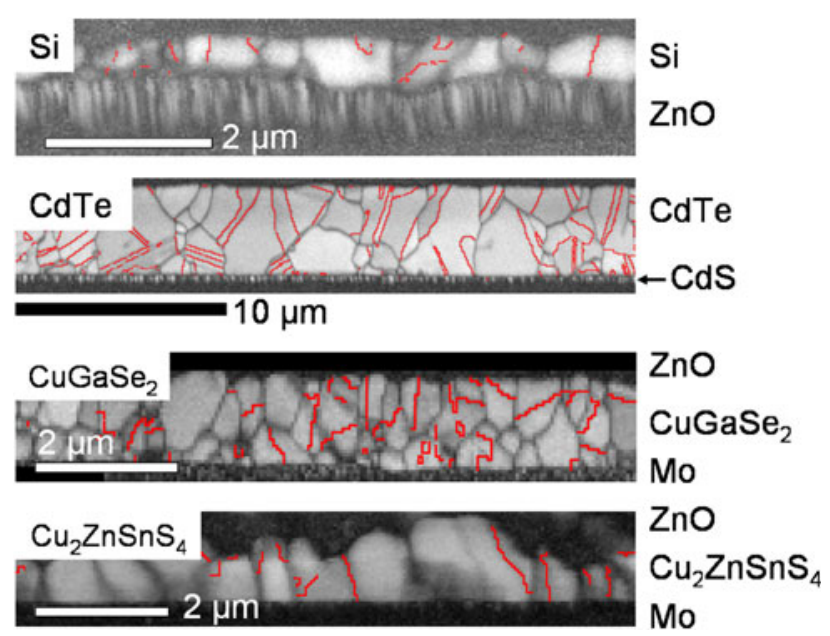

Fig. 3. EBSD pattern-quality maps with $\Sigma 3$ grain boundaries highlighted by red lines, acquired on cross sections of Si/ZnO/glass, Au/ $\mathrm{CdTe} / \mathrm{CdS} / \mathrm{SnO}_{2}:$ In/glass, $\mathrm{ZnO} / \mathrm{CdS} / \mathrm{CuGaSe}_{2} / \mathrm{Mo} / \mathrm{glass}$, and $\mathrm{ZnO} /$ $\mathrm{CdS} / \mathrm{Cu}_{2} \mathrm{ZnSnS}_{4} / \mathrm{Mo} /$ glass solar-cell stacks (Color figure online). layers obtained by interrupting growth processes, monitored by energy-dispersive x-ray spectrometry at a synchrotron beam-line. Distinct changes of positions and shapes of x-ray diffraction peaks during the growth have been related to changes in microstructure as detected by means of EBSD. ${ }^{16-18}$ In combination with energy-dispersive x-ray spectrometry, EBSD enables unambiguous identification of secondary phases in $\mathrm{CuInS}_{2}{ }^{19}$ and in $\mathrm{Cu}_{2} \mathrm{ZnSnS}_{4}{ }^{20}$

Correct indexing of the local orientations is an issue for $\mathrm{Cu}(\mathrm{In}, \mathrm{Ga})(\mathrm{S}, \mathrm{Se})_{2}$ and $\mathrm{Cu}_{2} \mathrm{ZnSn}(\mathrm{S}, \mathrm{Se})_{4}$ thin films with tetragonal crystal structures and (for certain compositions) ratios of the lattice constants $c / a$, which are very close to 2 . It has been shown ${ }^{21}$ that revealing the pseudosymmetry is possible in cases for which the deviation of $c / a$ from 2 is not larger than about $2 \%$. Further improvements of the indexing routines in EBSD software packages would be required in order to reveal the pseudosymmetry also for even smaller deviations.

\section{STRAIN MAPPING USING STORED EBSD PATTERNS}

By the evaluation of small shifts of the zone axes in EBSD patterns, distributions of strain and lattice rotations within individual grains can be calculated via a cross-correlation routine, using one diffraction pattern within a grain as Ref. 22. Figure 4 shows an EBSD orientation distribution map (Fig. 4a) and a corresponding distribution of the $\varepsilon_{22}$ strain tensor component within an individual grain, as calculated by the software CrossCourt 3 (Fig. 4b). In the largest part of the grain, the residual strain exhibits values of only few $0.1 \%$, which is well expected in view of the rather small grain sizes and the high density of grain boundaries, which compensate in part strain introduced during growth and cooling down of the thin film.

The impact of strain on the charge-carrier collection in thin-film solar cells is a matter of current research work. Strain distributions are closely linked to the presence of dislocations. It has been shown that in $\mathrm{Cu}(\mathrm{In}, \mathrm{Ga}) \mathrm{Se}_{2}$ layers, these linear defects are of considerable concern since their densities are influenced substantially by In/Ga gradients. ${ }^{23}$ Access to the presence and densities of dislocations in individual submicron grains within thin films by means of SEM and related techniques has still not been obtained on a routine basis.

\section{THREE-DIMENSIONAL EBSD}

By alternating FIB slicing and EBSD acquisitions, three-dimensional EBSD data cubes can be reconstructed from corresponding stacks of the recorded two-dimensional EBSD maps. An example of such a three-dimensional data cube of a $\mathrm{CuInS}_{2}$ thin film within a complete solar-cell stack is given in Fig. 5. 

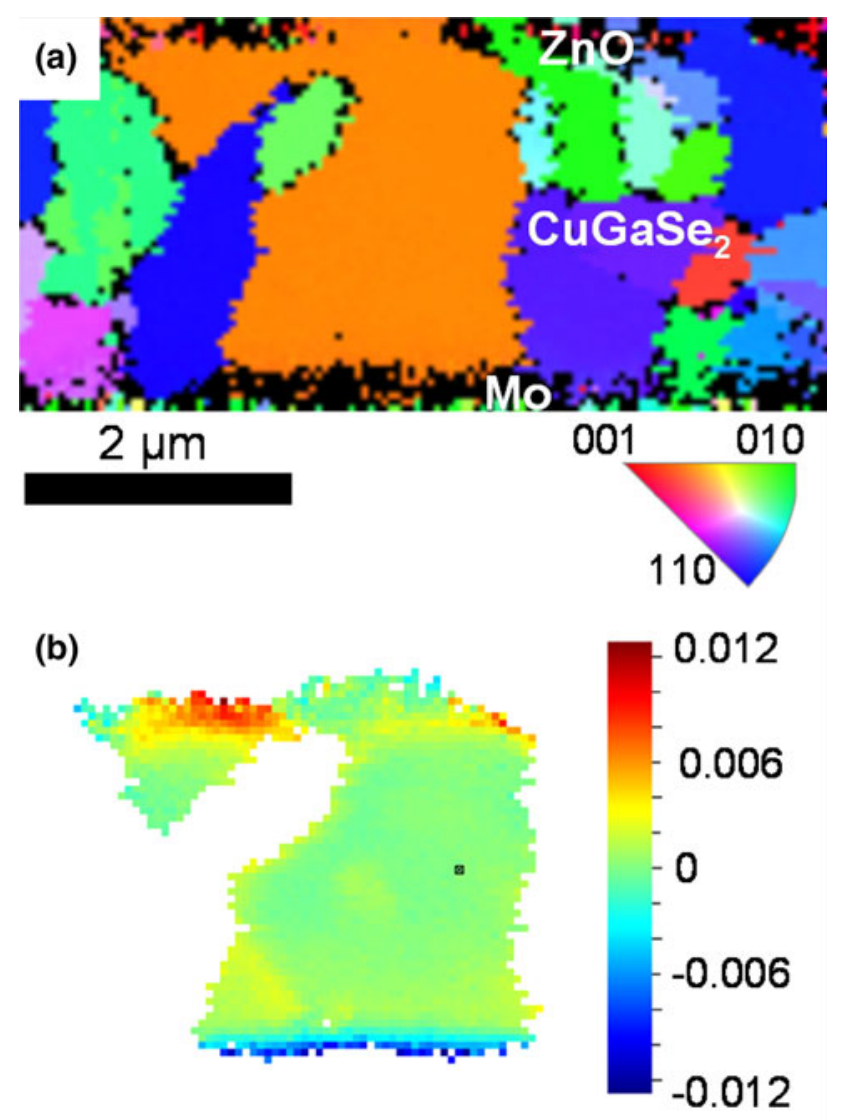

Fig. 4. EBSD orientation-distribution map obtained on a $\mathrm{ZnO} / \mathrm{CdS} /$ $\mathrm{CuGaSe}_{2} / \mathrm{Mo} /$ glass cross section (a), and corresponding distribution of the $\varepsilon_{22}$ strain tensor component (b), calculated using the software CrossCourt 3 .

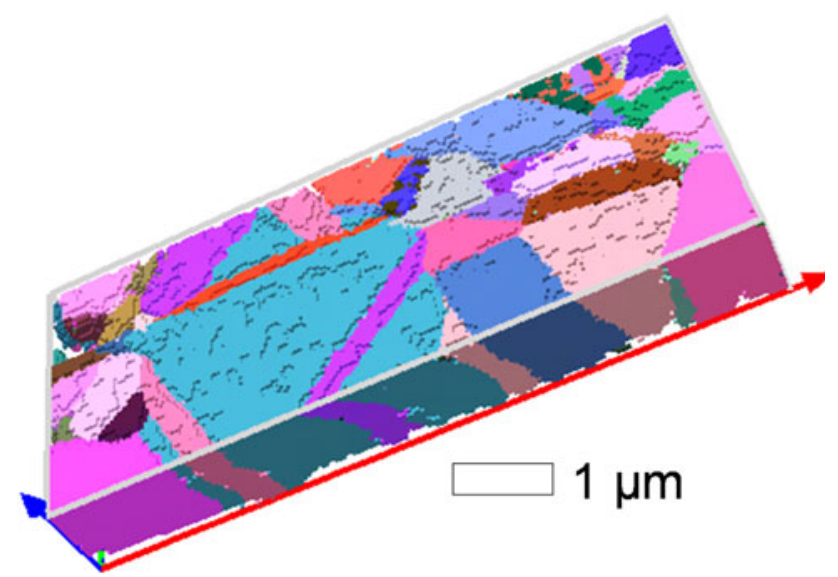

Fig. 5. Three-dimensional EBSD data cube, reconstructed from 20 individual two-dimensional EBSD maps acquired in plan-view on a $\mathrm{CulnS}_{2}$ thin film (deposited on Mo/glass substrates). The distances between the individual slices removed by focused ion beam (and in the presence of $\mathrm{XeF}_{2}$ ) were about $100 \mathrm{~nm}$. Figure taken from Ref. 5.

It is important to note that such three-dimensional representations of the microstructures of thin films are not only useful for a complete view on grain sizes but also on secondary phases or precipitates buried below a specimen surface. Also when combining EBSD with other SEM techniques such as EBIC and CL, it is helpful to gather information about the microstructure in three dimensions. The reason for this fact is that EBSD probes only the top 20-50 $\mathrm{nm}$ close to the surface in materials applied for thin-film solar cells, while EBIC and CL signals result from processes within several $100 \mathrm{~nm}$ or even few micrometers deep in the active absorber layers, depending on the diffusion lengths of the chargecarriers generated by the electron beam and on the electron-beam energy. To interpret these EBIC and CL signals correctly, acquisitions of three-dimensional EBSD data are of great advantage. For example, it is possible to reconstruct how grain boundaries proceed into the depth of a thin film and thus to attribute certain changes in EBIC and CL signals to the presence and inclination of these grain boundaries.

\section{EBSD COMBINED WITH OTHER SCANNING MICROSCOPY TECHNIQUES}

The previous sections presented various details on microstructural properties that can be obtained by means of EBSD. However, for optoelectronic devices such as solar cells, it is essential to furthermore analyze structure-property relationships in these devices. As a solar cell is a power-conversion device, the limiting factors for the light-induced current density and voltage have to be identified and amended, in order to improve the solar-cell performance.

One possible source for limitations in current density and voltage for thin-film solar cells are extended structural defects in the active absorber layers. When analyzing these defects, it is important to localize them unambiguously and, if possible, even to classify them. Exactly this possibility is provided by EBSD when applied on grain boundaries.

In recent years, particularly grain boundaries in $\mathrm{Cu}(\mathrm{In}, \mathrm{Ga})(\mathrm{S}, \mathrm{Se})_{2}$ thin films have been analyzed extensively by means of EBSD in combination with various scanning microscopy techniques on identical specimen positions. Before giving a brief overview of this work, it is important to note that optoelectronic characterization techniques exhibit various information depths. While SPM techniques (e.g., KPFM, SSRM, and SCM) probe the top monolayers of samples, the signals acquired by the SEM methods EBIC and CL arise from processes within several $100 \mathrm{~nm}$ or even few micrometers within the studied material. Sadewasser et al. ${ }^{24}$ reported that even though various SEMs as well as scanning probe and tunneling techniques were applied on grain boundaries within absorber layers from identical growth processes, it was not possible to conclude on one consistent grain boundary model from all these results. 
Another issue is that EBIC measurements have so far been performed at room temperature, while all reported CL measurements in the literature have been conducted at very low temperatures of about $10 \mathrm{~K}$ (CL measurements at room temperature suffer from very low signals). Since the charge-carrier dynamics within these temperature ranges are considerably different, conclusions on optoelectronic properties of grain boundaries from combined EBIC and CL analyses, even if performed on identical specimen positions, are rather difficult.

It is a consistent result from all SEM ${ }^{24-28}$ and SPM measurements ${ }^{29,30}$ applied (in combination with EBSD) on grain boundaries in $\mathrm{Cu}(\mathrm{In}, \mathrm{Ga})(\mathrm{S}, \mathrm{Se})_{2}$ thin films that most $\Sigma 3$ (twin) boundaries do not exhibit substantial changes in the measured signals. Thus, most of these high-symmetrical types of grain boundaries are considered electrically inactive. For a $\mathrm{CuGaSe}_{2}$ bicrystal with a $\Sigma 3$ twin boundary, it was found by means of KPFM combined with Hall measurements that this high-symmetrical defect exhibits charge neutrality with a small barrier for holes of about $30 \mathrm{meV}$. $^{31}$

A different situation is found for random grain boundaries. Figure 6 gives an example of combined EBSD and EBIC acquisitions at the identical specimen position. The EBIC signal is enhanced in the space-charge region of the $p-n$ junction of the solar cell owing to field-driven charge carrier collection within this region. Such measurements at (random) grain boundaries in identical $\mathrm{Cu}(\mathrm{In}, \mathrm{Ga})(\mathrm{S}, \mathrm{Se})_{2}$ thin films yielded increased and decreased EBIC signals $^{24-27}$ at different grain boundaries. Thus, it is not possible to draw unambiguous conclusions about the influence of grain boundaries on charge-carrier collection from these measurements.

For corresponding CL signals, they have been reported to be always reduced at random grain boundaries. ${ }^{28,32,33}$ Decreases are found to be as large as 30-50 rel.\%, while the luminescence maxima exhibit shifts only a few meV. An example of combined EBSD and CL acquisitions at identical positions is shown in Fig. 7. Apparently, the CL signals are rather inhomogeneous, also within individual grains. The regions with different CL intensity indicate the presence of extended structural defects, which cannot be detected by means of EBSD (for further details on this issue, the reader is referred to Ref. 26).

Also by means of KPFM, different changes in contact potential, which may be attributed to changes in work function (when using an appropriate reference material), are found at different random grain boundaries ${ }^{27}$ (see Fig. 8). The changes in work functions may be interpreted as potential barriers at random grain boundaries, which exhibit positive or negative values. Several random grain boundaries do not show any changes in the work function above noise level (Fig. 8).

In view of the complex scenario from the EBIC, $\mathrm{CL}$, and KPFM measurements at random grain
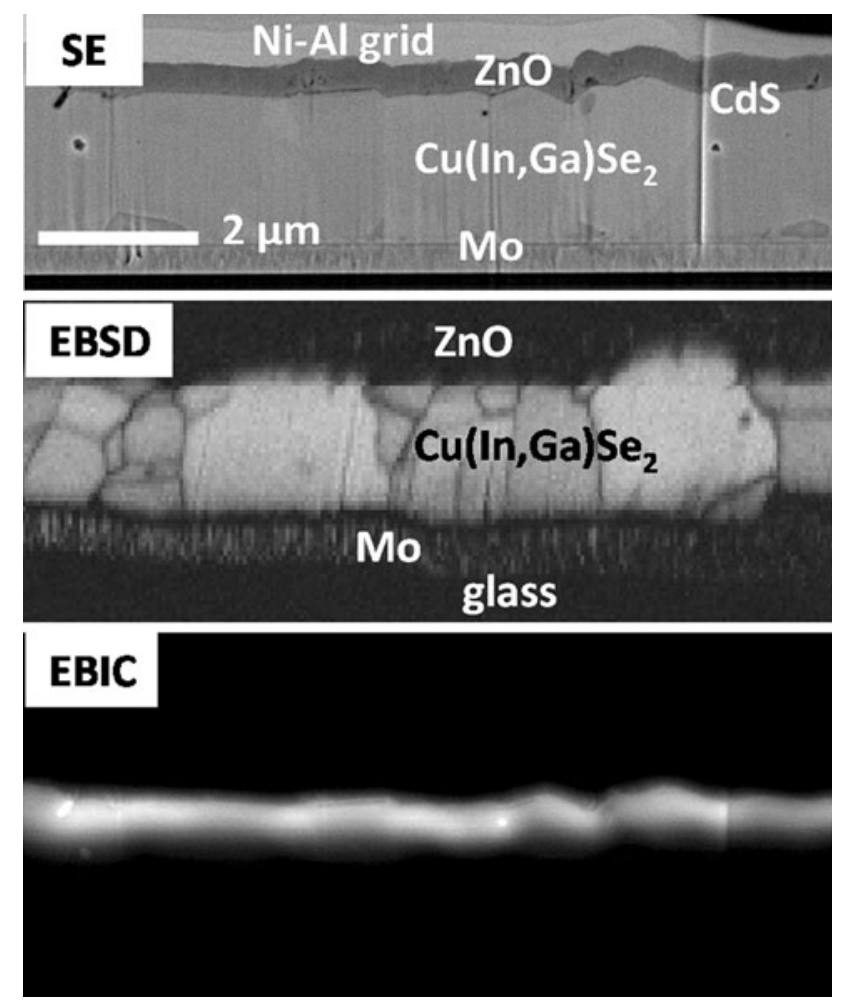

Fig. 6. Secondary-electron (SE) image, EBSD pattern-quality map, as well as EBIC image (at $10 \mathrm{kV}$ and $200 \mathrm{pA}$ ), all acquired on the identical position of a cross-sectional specimen prepared from a $\mathrm{ZnO} / \mathrm{CdS} / \mathrm{Cu}(\mathrm{In}, \mathrm{Ga}) \mathrm{Se}_{2} / \mathrm{Mo} / \mathrm{glass}$ stack.

boundaries, it can be expected that the chemical nature of these extended structural defects is likewise diverse. Indeed, compositional changes are found in $\mathrm{Cu}(\mathrm{In}, \mathrm{Ga}) \mathrm{Se}_{2}$ thin films within regions around random grain boundaries that have widths of smaller than $1 \mathrm{~nm} .{ }^{34}$ This is, the atomic planes of neighboring grains that meet at random grain boundaries in $\mathrm{Cu}(\mathrm{In}, \mathrm{Ga}) \mathrm{Se}_{2}$ thin films are considered reconstructed. It has been found ${ }^{34,35}$ that the changes in composition and thus the reconstruction is always different for different (random) grain boundaries, even in identical $\mathrm{Cu}(\mathrm{In}, \mathrm{Ga}) \mathrm{Se}_{2}$ thin films. This result agrees well with the diverse EBIC, $\mathrm{CL}$, and KPFM signals obtained. It can be understood in terms of a large number of point defects in $\mathrm{Cu}(\mathrm{In}, \mathrm{Ga}) \mathrm{Se}_{2}$ thin films, which segregate to the (random) grain boundaries. When soda-lime glass is used as substrates, even further point defects related to impurities such as $\mathrm{Na}, \mathrm{O}$, and $\mathrm{K}$, which diffuse from the glass substrate into the $\mathrm{Cu}(\mathrm{In}, \mathrm{Ga})$ $\mathrm{Se}_{2}$ thin films, contribute to the grain-boundary compositions. ${ }^{35}$

The complex scenario of the compositional and optoelectronic properties of random grain boundaries in $\mathrm{Cu}(\mathrm{In}, \mathrm{Ga}) \mathrm{Se}_{2}$ thin films is difficult to be translated into a corresponding energy-band diagram and eventually into a two- or three-dimensional device simulation, which ultimately would give direct insight into how (random) grain bound- 

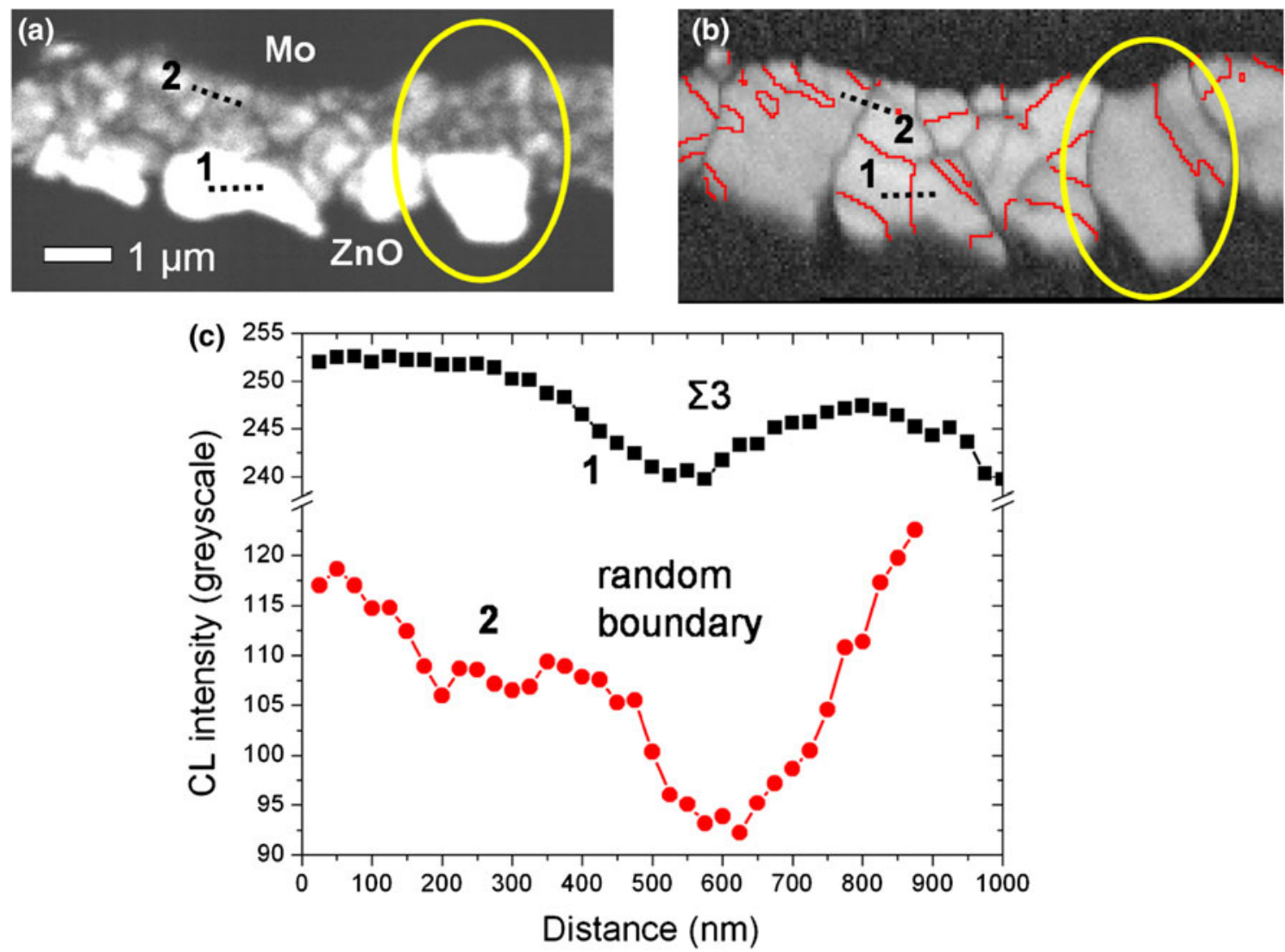

Fig. 7. (a) Monochromatic CL image at $820 \mathrm{~nm}$, and (b) EBSD pattern-quality map with $\Sigma 3$ (twin) boundaries highlighted by intensified red lines. A grain is highlighted by yellow circles in the CL image and the EBSD map. (c) Profiles extracted from the positions marked with dotted lines, across a $\Sigma 3$ (1) and a random grain boundary (2). Adapted from Ref. 28 (Color figure online).

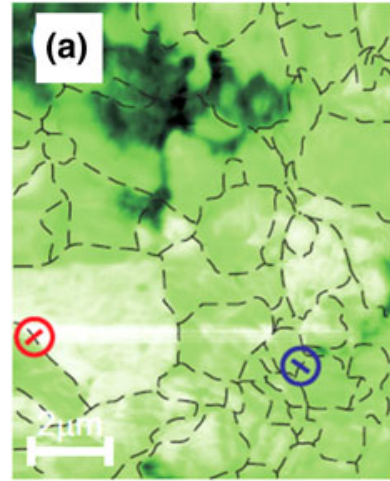

$4.61 \mathrm{eV}$

$5.19 \mathrm{eV}$

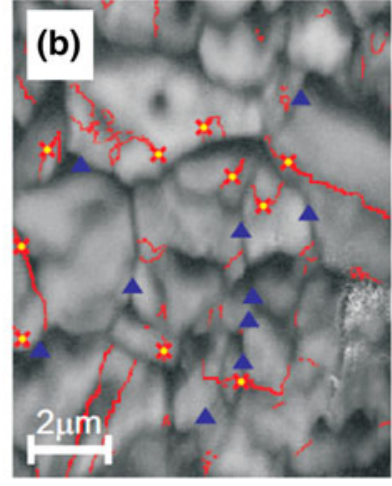

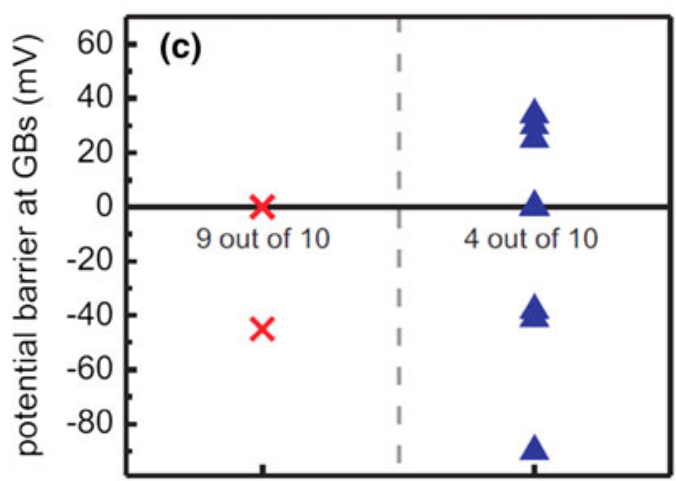

$\Sigma 3 \mathrm{GBs}$

non- 23 GBs

Fig. 8. KPFM work function image (a) and EBSD pattern-quality map (b) with $\Sigma 3$ (twin) boundaries highlighted by red solid lines, from an identical location on a CulnSe $e_{2}$ thin film. The positions of $\Sigma 3$ and non- $\Sigma 3$ grain boundaries analyzed in (c) are indicated by red crosses with yellow dots and by blue triangles in (b). Adapted from Ref. 29 (Color figure online).

aries affect the device performance. Corresponding work is currently in progress.

\section{CONCLUSIONS}

In the present work, it was shown how to access various types of information on microstructural properties of thin-film solar cells by means of EBSD measurements. Moreover, it was outlined how EBSD contributes to the analysis of structureproperty relationships in these solar cells, especially when combined with other SEM and SPM techniques. It is the focus of future research to achieve a better understanding of how microstructure devel- 
Electron Backscatter Diffraction: An Important Tool for Analyses of Structure-Property Relationships in Thin-Film Solar Cells

ops during growth, a task that will be conducted also by use of EBSD on specimens from broken-off growth processes.

\section{ACKNOWLEDGEMENTS}

The authors are grateful to U. Bloeck, J. Bundesmann, B. Bunn, C. Ferber, C. Förster, C.A. Kaufmann, M. Kirsch, H. Kropf, T. Münchenberg, J. Schniebs, P. Schubert-Bischoff, and Harald Stapel for solar-cell production, specimen preparation, and technical support in measurements at the SEM. Special thanks are due to S. Bücheler, EMPA, Dübendorf, Switzerland, as well as to T. Sontheimer, T. Rissom, B. Marsen, J. Klaer, and B. Schubert, HZB, Berlin, Germany, for providing solar cells for EBSD measurements. This work was supported in part by the Virtual Helmholtz Institute VI-520 "Microstructure Control for Thin-Film Solar Cells".

\section{REFERENCES}

1. A New World Record for Solar Cell Efficiency (Dübendorf: EMPA, 2013), http://www.empa.ch/plugin/template/empa/*/ 131441. Accessed 15 April 2013.

2. First Solar Sets New World Record for CdTe Solar Cell Efficiency (Tempe, AZ: First Solar, 2013), http://investor. firstsolar.com/releasedetail.cfm?ReleaseID=743398. Accessed 15 April 2013.

3. T.K. Todorov, J. Tang, S. Bag, O. Gunawan, T. Gokmen, Y. Zhu, and D.B. Mitzi, Adv. Energy Mater. 3, 34 (2012).

4. New World Record Efficiency for Thin Film Silicon Solar Cells (Lausanne: EPFL, 2013), http://actu.epfl.ch/news/newworld-record-efficiency-for-thin-film-silicon-\%. Accessed 15 April 2013.

5. J. Poortmans and V. Arkhipov, eds., Thin Film Solar Cells: Fabrication, Characterization, and Applications, 1st ed. (Chichester: Wiley, 2006).

6. Y. Hamakawa, ed., Thin-Film Solar Cells: Next-Generation Photovoltaics and Its Applications, 1st ed., Springer Series in Photonics, vol. 13 (Berlin: Springer, 2004).

7. D. Abou-Ras, B. Marsen, T. Rissom, F. Frost, H. Schulz, F. Bauer, V. Efimova, V. Hoffmann, and A. Eicke, Micron 43, 470 (2012).

8. H. Grimmer, W. Bollmann, and D.H. Warrington, Acta Crystallogr. A 30, 197 (1974).

9. D. Abou-Ras, S. Schorr, and H.-W. Schock, J. Appl. Crystallogr. 40, 841 (2007)

10. D. Abou-Ras, C.T. Koch, V. Küstner, P.A. van Aken, U. Jahn, M.A. Contreras, R. Caballero, C.A. Kaufmann, R. Scheer, T. Unold, and H.-W. Schock, Thin Solid Films 517, 2545 (2009).

11. D. Abou-Ras, M. Nichterwitz, C.A. Kaufmann, S. Schorr, and H.-W. Schock, Thin-Film Compound Semiconductor Photovoltaics 2007, ed. T. Gessert, S. Marsillac, T. Wada, K. Durose, and C. Heske (Warrendale, PA: TMS, 2007), pp. Y9.3.1-Y9.3.6.

12. D. Abou-Ras and K. Pantleon, Phys. Status Solidi 1, 187 (2007).
13. D. Abou-Ras, M.A. Contreras, R. Noufi, and H.-W. Schock, Thin Solid Films 517, 2218 (2009).

14. O. Cojocaru-Mirédin, P.-P. Choi, D. Abou-Ras, S.S. Schmidt, R. Caballero, and D. Raabe, J. Photovolt. 1, 207 (2011).

15. W. Witte, D. Abou-Ras, and D. Hariskos, Appl. Phys. Lett. 102, 051607 (2013).

16. H. Rodriguez-Alvarez, R. Mainz, B. Marsen, D. Abou-Ras, and H.W. Schock, J. Appl. Crystallogr. 43, 1053 (2010).

17. D. Thomas, R. Mainz, H. Rodriguez-Alvarez, B. Marsen, D. Abou-Ras, M. Klaus, C. Genzel, and H.-W. Schock, Thin Solid Films 519, 7193 (2011).

18. H. Rodriguez-Alvarez, R. Mainz, R. Caballero, D. Abou-Ras, M. Klaus, S. Gledhill, A. Weber, C. Kaufmann, and H.-W. Schock, Sol. Energy Mater. Sol. Cells 116, 102 (2013).

19. D. Abou-Ras, M. Nichterwitz, R. Caballero, C.A. Kaufmann, T. Unold, S. Schorr, R. Scheer, J. Klaer, and H.-W. Schock, Proceedings of the 22nd European Photovoltaic Solar Energy Conference and Exhibition, Milan, Italy, September 3-7, 2007 (Munich: WIP, 2007), pp. 1911-1914.

20. A. Ennaoui, M. Lux-Steiner, A. Weber, D. Abou-Ras, I. Kötschau, H.-W. Schock, R. Schurr, A. Hölzing, S. Jost, R. Hock, T. Voß, J. Schulze, and A. Kirbs, Thin Solid Films 517, 2511 (2009).

21. D. Abou-Ras, J. Gibmeier, G. Nolze, A. Gholinia, and P. Konijnenberg, Cryst. Res. Technol. 43, 234 (2008).

22. A.J. Wilkinson, G. Meaden, and D.J. Dingley, Mater. Sci. Technol. 22, 1271 (2006).

23. J. Dietrich, D. Abou-Ras, T. Rissom, T. Unold, H.-W. Schock, and C. Boit, J. Photovolt. 2, 364 (2012).

24. S. Sadewasser, D. Abou-Ras, D. Azulay, R. Baier, I. Balberg, D. Cahen, S. Cohen, K. Gartsman, G. Karuppiah, J. Kavalakkatt, W. Li, O. Millo, T. Rissom, Y. Rosenwaks, H.-W. Schock, A. Schwarzman, and T. Unold, Thin Solid Films 519, 7341 (2011).

25. M. Nichterwitz, D. Abou-Ras, K. Sakurai, J. Bundesmann, T. Unold, R. Scheer, and H.W. Schock, Thin Solid Films 517, 2554 (2009).

26. M. Kawamura, T. Yamada, N. Suyama, A. Yamada, and M. Konagai, Jpn. J. Appl. Phys. 49, 062301 (2010).

27. D. Abou-Ras, J. Dietrich, J. Kavalakkatt, M. Nichterwitz, S.S. Schmidt, C.T. Koch, R. Caballero, J. Klaer, and T. Rissom, Sol. Energy Mater. Sol. Cells 95, 1452 (2011).

28. D. Abou-Ras, U. Jahn, J. Klaer, M. Nichterwitz, T. Unold, and H.-W. Schock, J. Appl. Phys. 107, 014311 (2010).

29. R. Baier, D. Abou-Ras, T. Rissom, M.C. Lux-Steiner, and S. Sadewasser, Appl. Phys. Lett. 99, 172102 (2011).

30. C.-S. Jiang, M.A. Contreras, I. Repins, H.R. Moutinho, Y. Yan, M.J. Romero, L.M. Mansfield, R. Noufi, and M.M. Al-Jassim, Appl. Phys. Lett. 101, 033903 (2012).

31. S. Siebentritt, S. Sadewasser, M. Wimmer, C. Leendertz, T. Eisenbarth, and M.C. Lux-Steiner, Phys. Rev. Lett. 97, 146601 (2006).

32. J. Kavalakkatt, D. Abou-Ras, J. Haarstrich, C. Ronning, M. Nichterwitz, R. Caballero, T. Rissom, T. Unold, R. Scheer, and H.W. Schock, unpublished work.

33. M. Müller, D. Abou-Ras, T. Rissom, F. Bertram, and J. Christen, unpublished research.

34. D. Abou-Ras, B. Schaffer, M. Schaffer, S.S. Schmidt, R. Caballero, and T. Unold, Phys. Rev. Lett. 108, 075502 (2012).

35. D. Abou-Ras, S.S. Schmidt, R. Caballero, T. Unold, H.-W. Schock, C.T. Koch, B. Schaffer, M. Schaffer, P. Choi, and O. Cojocaru-Mirédin, Adv. Eng. Mater. 2, 992 (2012). 